\title{
Fatores motivacionais para o trabalho em instituições de ensino superior
}

O estudo da motivação tornou-se importante para as organizações, pois os colaboradores motivados tendem a permanecerem por mais tempo na empresa, além de produzirem com mais eficiência, assim, impactando no clima organizacional que tende a melhorar constantemente. Diante disso, a presente pesquisa teve como objetivo geral identificar os fatores motivacionais apresentados por colaboradores de Instituições de Ensino Superior (IES) por meio de uma revisão da literatura. Para tanto, buscou-se descrever os fatores para satisfação dos colaboradores das instituições de ensino superior; verificar as estratégias criadas para motivação dos colaboradores nas Instituições; identificar as principais teorias da motivação que fundamentam as estratégias da gestão de pessoas para motivar os colaboradores. Sobre a esfera metodológica adotou-se uma pesquisa de natureza básica com objetivo exploratório, utilizando-se da abordagem qualitativa, configurando-se como revisão de literatura sistemática. Com relação aos resultados obtidos verificou-se as variáveis que motivam os colaboradores dentro das IES como a presença de treinamento e desenvolvimento na organização, comunicação mais eficiente, evitando possíveis ruídos e conflitos entre as pessoas, além da percepção positiva dos colaboradores referente ao reconhecimento recebido. Também é perceptível, as relações interpessoais satisfatórias nas instituições, promovendo um ambiente de trabalho mais agradável e proveitoso para os funcionários das IES. Assim, pode-se concluir que as variáveis apresentadas neste estudo contribuem para a satisfação dos colaboradores nas IES.

Palavras-chave: Motivação; Satisfação; Instituições de ensino superior; Colaboradores.

\section{Motivational factors for working in higher education institutions}

The study of motivation has become important for organizations, as motivated employees tend to stay longer in the company, in addition to producing more efficiently, thus impacting on the organizational climate that tends to constantly improve. Given this, the present research had as general objective to identify the motivational factors presented by collaborators of Higher Education Institutions (HEls) through a literature review. To this end, we sought to describe the factors for the satisfaction of employees of higher education institutions; verify the strategies created to motivate employees in the Institutions; identify the main theories of motivation that underpin the strategies of people management to motivate employees. Regarding the methodological sphere, research of a basic nature was adopted with an exploratory objective, using the qualitative approach, configuring itself as a systematic literature review. Regarding the results obtained, the variables that motivate employees within HEls were verified, such as the presence of training and development in the organization, more efficient communication, avoiding possible noise and conflicts between people, in addition to the positive perception of employees regarding the recognition received. It is also noticeable, the satisfactory interpersonal relationships in the institutions, promoting a more pleasant and profitable work environment for the employees of the HEls. Thus, it can be concluded that the variables presented in this study contribute to the satisfaction of employees in HEls.

Keywords: Motivation; Satisfaction; Higher Education Institutions; Employees.

Topic: Ensino Superior, Pesquisa e Extensão

Reviewed anonymously in the process of blind peer.
Received: $19 / 04 / 2021$

Approved: 20/07/2021
Leonardo Ferreira de Azevedo (iD)

Centro Universitário Vale do Salgado, Brasil http://lattes.cnpq.br/2475632660990489 http://orcid.org/0000-0002-6416-697X leomises99@gmail.com

Maria Waldilene Sousa Cavalcante (iD) Centro Universitário Vale do Salgado, Brasil http://lattes.cnpq.br/0494646222507948 http://orcid.org/0000-0002-5257-9451 waldilenesouza@univs.edu.br

Antoniel dos Santos Gomes Filho (iD Centro Universitário Vale do Salgado, Brasil http://lattes.cnpq.br/9563145614494252 http://orcid.org/0000-0003-2230-4315 antoniel.historiacomparada@gmail.com
Referencing this:

AZEVEDO, L. F.; TEIXEIRA, M. W. S.; GOMES FILHO, A. S.. Fatores motivacionais para o trabalho em instituições de ensino superior. Educationis, v.9, n.2, p.1-17, 2021. DOI: http://doi.org/10.6008/CBPC2318-3047.2021.002.0001 


\section{INTRODUÇÃO}

A motivação no trabalho torna-se essencial para o sucesso no ambiente profissional. A motivação consiste em um "processo que mobiliza o organismo para ação, a partir de uma relação estabelecida entre o ambiente, a necessidade e o objeto de satisfação" (BOCK et al., 1999). Desse modo, há uma diversidade de fatores internos e externos que impulsionam a pessoa a atingir os seus objetivos. Assim, é importante entender os fatores que motivam as pessoas no ambiente de trabalho. Destaca-se que existem fatores divergentes que motivam os colaboradores a produzirem de uma maneira melhor. Nesse contexto, torna-se importante manter os colaboradores motivados, trazendo resultados satisfatórios tanto para os colaboradores, quanto para a organização (ANDRADE et al., 2009).

A universidade é um local em que se produz conhecimento, formando cidadãos e profissionais com competências para transformar a realidade em que o mesmo vive (MOREIRA et al., 2018). No tocante a motivação no âmbito das instituições de Ensino Superior (IES) é necessário que exista uma interação contínua entre os profissionais dessa organização com o intuito de manter esses motivados. Assim, o clima organizacional, presente, se tornará mais positivo para os colaboradores produzirem com qualidade e eficiência (SIQUEIRA, 2008).

O papel da motivação no ambiente de trabalho se torna cada vez mais essencial para a gestão de pessoas, pois é preciso motivar os colaboradores com o intuito de alcançarem os objetivos da empresa (SILVA et al., 2015). No entanto, é preciso que o gestor de pessoas busque identificar os fatores motivacionais dos colaboradores da organização. Assim, inicialmente aponta-se como fatores motivacionais para os colaboradores, de acordo com Carvalho et al. (2013), a remuneração e os benefícios sociais recebidos, as condições físicas e psicológicas do trabalho e a questão da segurança presente no ambiente organizacional. Dessa forma, o presente trabalho teve como problemática: quais são os fatores motivacionais apresentados por colaboradores de instituições de ensino superior no ambiente de trabalho?

A presente proposta de estudo com a temática da motivação nas IES tem como justificativa, no âmbito acadêmico, estimular a produção científica referente a temática da motivação no âmbito organizacional, assim, enriquecendo com informações relevantes, tendo o intuito de contribuir numa melhor formação dos futuros profissionais. Além disso, a pesquisa traz como contribuição para as organizações de ensino superior, identificar quais os fatores que motivam os colaboradores a produzirem com qualidade e eficiência dentro dessas organizações. Para o pesquisador irá proporcionar possibilidades de análises da temática abordada, bem como um conhecimento com relação aos fatores que motivam os colaboradores. Por fim, a pesquisa traz como impacto para a sociedade, colaborar no entendimento da importância que os colaboradores têm para as organizações e a necessidade de mantê-los motivados e satisfeitos no ambiente de trabalho.

A pesquisa objetivou identificar os fatores motivacionais apresentados por colaboradores de Instituições de Ensino Superior (IES) a partir de uma revisão da literatura. Tiveram como objetivos específicos descrever os fatores para satisfação dos colaboradores das instituições de ensino superior; verificar as 
estratégias criadas para motivação dos colaboradores nas Instituições; identificar as principais teorias da motivação que fundamentam as estratégias da gestão de pessoas para motivar os colaboradores.

\section{REVISÃO TEÓRICA}

Este tópico tem como foco apresentar as características da motivação e da satisfação dos colaboradores no ambiente de trabalho, que de acordo com Ribeiro et al. (2018), a motivação dos funcionários é uma preocupação que existe a muito tempo dentro das organizações e para entendê-la é preciso identificar as variáveis que a influenciam. Também apresenta as principais teorias que baseiam a temática da motivação no âmbito organizacional. Por fim, é discutido sobre a situação da educação superior no Brasil.

\section{Motivação e satisfação no trabalho}

Pode-se dizer que a motivação é uma força responsável por incentivar os indivíduos a agirem de modo específico em busca do alcance de um determinado objetivo. Nesse contexto, a motivação é responsável por fazer uma pessoa se esforçar para buscar o cumprimento de suas metas (ROBBINS, 2008).

Segundo Chiavenato (2010), motivo é tudo que influencia uma pessoa a portar-se de determinada maneira, dando origem a um comportamento distinto. Assim, para cada ação cometida por um indivíduo, existirá um motivo específico que justifique tal ação. Além disso, Oliveira (2015), fala que uma pessoa motivada traz consigo inspiração, seu humor tende a melhorar e acaba contagiando os seus colegas de trabalho. Assim, é importante manter os colaboradores motivados para que o ambiente de trabalho esteja propício a ter resultados satisfatórios tanto para os colaboradores, quanto para a organização. Santos (2010), aponta que:

O estudo sobre motivação revela-nos os aspectos que nos impulsionam em nossos comportamentos. [...] nem sempre revelam exatamente quais os fatores que estão incluídos na determinação do comportamento humano. [...] a própria motivação revela-nos a força existente em algumas ações e a manutenção desses comportamentos dá-nos o grau de intensidade que a pessoa apresenta. (SANTOS, 2010)

Uma ação que pode não motivar de um indivíduo, não necessariamente significa que terá a mesma consequência sob outro, isto acontece, pois, o comportamento dos indivíduos é derivado de diferentes fatores psicológicos, ou seja, cada indivíduo tem fatores motivacionais diversos, que os movem a agir de determinada maneira, obtendo assim a satisfação (VERGARA et al., 2006).

A satisfação é definida pela interação de diversos fatores como as relações interpessoais do indivíduo no trabalho e sua capacidade de compreender a importância do trabalho. Além disso, quando existe a insatisfação por parte dos colaboradores, é preciso que a organização crie medidas para diminuí-la, como criar programas de interação entre os colaboradores, planos de carreira e incentivo para uma maior participação dos profissionais nas tomadas de decisões gerenciais (MARQUEZE et al., 2005).

Para Giauque et al. (2012), a satisfação no trabalho acontece quando é percebido pelo colaborador um equilíbrio entre os seus esforços no trabalho e o conjunto de benefícios oferecidos pela organização. Logo, a satisfação está relacionada ao sentimento de justiça, que é sentido pelo colaborador. Para Locke 
(1969) em estudo considerado clássico sobre o tema, a satisfação é resultante da avaliação que o colaborador tem em relação ao seu trabalho dentro da organização. Vale ressaltar que a satisfação é um sentimento que resulta tanto de fatores internos, quanto externos, sendo determinantes para a satisfação ou insatisfação do colaborador no ambiente de trabalho. Assim, pode-se exemplificar como fatores internos e externos, de acordo com Hencke et al. (2017), o reconhecimento por parte dos superiores, o cargo ocupado, o sentimento de responsabilidade e o ambiente de trabalho como fatores internos e como fatores externos pode citar os salários recebidos, a estabilidade e os incentivos oferecidos pela organização.

De acordo com Siqueira (2008), a satisfação no trabalho se caracteriza deste modo:

Investigar satisfação no trabalho significa avaliar o quanto os retornos ofertados pela empresa em forma de salários e promoções, o quanto a convivência com os colegas e as chefias e o quanto a realização das tarefas propiciam ao empregado sentimentos gratificantes ou prazerosos. (SIQUEIRA, 2008)

Conforme Robbins (2009), a satisfação influencia na atitude do colaborador, pois quando ele se sente satisfeito com o trabalho, demonstra boas atitudes, assim, ao colaborador se sente satisfeito no trabalho, o mesmo irá superar o desempenho exigido e também ajudará os seus colegas a cumprirem com as obrigações dos cargos ocupados.

\section{Teorias da motivação}

Diante da temática da motivação no ambiente de trabalho, faz-se necessário apresentar as principais teorias elencadas nos livros e artigos clássicos e contemporâneos no campo das ciências administrativas, que são: A pirâmide das necessidades de Maslow, Teoria das necessidades adquiridas, Teoria X e Y de McGregor, Teoria bifatorial de Herzberg, Teoria da expectância de Victor Vroom e Teoria da equidade de Stacy Adams.

\section{A Pirâmide das Necessidades de Abraham Maslow}

Abraham Maslow foi um psicólogo estadunidense responsável pela elaboração da teoria da pirâmide das necessidades, ele nasceu em 1908 no bairro do Brooklyn em Nova York. Formou-se em Psicologia pela Universidade de Wisconsin-Madison, onde, posteriormente, fez seu mestrado e doutorado. Foi professor, lecionando nas seguintes instituições: Cornell University, Brooklyn College e Brandeis University. Ele é bastante conhecido por seu o autor do artigo: "A theory of human motivation" publicado em 1943 na Psychological Review, onde abordou pela primeira vez sobre a hierarquia das necessidades humanas. Em 1954, Maslow expressou completamente sua teoria no seu livro "Motivation and personality". Por fim, em 1970 foi vítima de um ataque cardíaco que ocasionou em sua morte na Califórnia.

De acordo com a abordagem de Maslow (1954), as necessidades humanas podem ser descritas em cinco principais categorias, que são: (01) Fisiológicas: fome, sede, moradia, relação sexual, dentre tantas outras necessidades; (02) Segurança: segurança e proteção física e/ou emocional; (03) Sociais: amizade, aceitação social e sentimento de pertencimento a um grupo; (04) Estima: status, realização, autonomia, amor próprio e reconhecimento; (05) Auto realização: sucesso e crescimento pessoal.

Para Chiavenato (2000), a abordagem da pirâmide das necessidades de Maslow, configura-se assim: 
Abraham Maslow apresentou uma teoria da motivação segundo a qual as necessidades humanas estão organizadas e dispostas em níveis, numa hierarquia de importância e influência e que pode ser visualizada como uma pirâmide. Na base da pirâmide estão as necessidades mais baixas (necessidades fisiológicas) e no topo, as necessidades mais elevadas (auto realização). (CHIAVENATO, 2000)

Conforme Vergara (2005a), Maslow explica que o indivíduo busca primeiramente suprir as necessidades fisiológicas e de segurança (necessidades primárias) para posteriormente, suprir as necessidades sociais, de estima e auto realização (necessidades secundárias), em forma de pirâmide. Existe uma divisão da pirâmide em duas partes, sendo explicada pela diferença da natureza dos fatores de motivação. As necessidades de nível mais baixo são satisfeitas por fatores externos ao indivíduo, que são chamadas de necessidades primárias. São considerados fatores externos: a remuneração, o ambiente de trabalho adequado e o sentimento de estabilidade no trabalho. Já as necessidades de nível mais alto são satisfeitas pelos fatores internos do indivíduo, que são chamadas de necessidades secundárias, são os fatores de realização, de se sentir bem consigo mesmo e ter o sentimento de ser importante para a organização (ROBBINS, 2002).

\section{Teoria X e Y de Douglas Mcgregor}

Douglas McGregor foi um engenheiro estadunidense, que estudou a teoria X e Y, ele nasceu em 1906 em Detroit, Michigan. Formou-se em Engenharia pela Rangoon Institute of Technology em 1932, posteriormente fez o seu mestrado e doutorado em Psicologia pela Harvard University. Posteriormente, tornou-se professor, lecionando na Harvard University e na Massachusetts Institute of Technology - MIT, sendo um dos primeiros docentes da escola de negócios, Sloan School of Management. Ele tem como principal livro "The human side of Enterprise", que trouxe como abordagem o estudo da teoria X e Y. Em 1967, no livro "Professional manager", em que foi elaborado baseado nas ideias do livro anterior, trazendo implicações comportamentais, sociais e psicológicas.

McGregor analisa dois comportamentos diferentes de administrar: o primeiro estilo tem como base métodos tradicionais e mecânicos, sendo intitulado de teoria X. Já o segundo estilo é baseado em concepções mais modernas em relação ao comportamento humano nas organizações, essa abordagem analisa o homem como um ser criativo, que gosta de trabalhar e que tem o desejo de receber responsabilidades, essa teoria é chamada de teoria Y (CHIAVENATO, 2000).

Para McGregor (1999), a teoria X explica que as metas dos colaboradores e da organização são diferentes e os colaboradores são motivados por fatores externos, como o salário, além do medo de receber punições. Porém, na teoria $\mathrm{Y}$, o colaborador é motivado tanto por fatores externos, quanto por fatores internos.

De acordo com Michel (2005), a teoria X se caracteriza dessa maneira:

O ser humano, em geral, não gosta intrinsecamente de trabalhar, e trabalha o mínimo possível; Por essa razão a maior parte das pessoas precisa ser coagida, vigiada, orientada, ameaçadas com castigos a fim de fazer o devido esforço para alcançar os objetivos da organização; O ser humano médio prefere ser dirigido, desejando evitar responsabilidades; é pouco ambicioso, procurando segurança acima de tudo; Empregados evitam responsabilidades e procurarão receber ordens formais, sempre que possível; A maioria dos 
trabalhadores põe a segurança acima de todos os fatores associados ao trabalho, exibindo pouca ambição. (MICHEL, 2005)

A teoria $Y$ representa um modelo moderno de administração com base na teoria comportamental, que sugere um estilo de liderança participativo e democrático, com base em valores sociais e humanísticos. Portanto, a teoria $Y$ traz a ideia de que os colaboradores são criativos e estão dispostos a receberem responsabilidades, assim, é necessário que exista uma liderança democrática que oportunize os colaboradores a participarem do processo para tomada de decisão (CHIAVENATO, 2007).

De acordo com Santos et al. (2010), no seu processo de análise da teoria X e Y, McGregor elaborou uma escala de filosofia gerencial, que tinha como função examinar todas as questões presentes. Assim, evitando criticar quem concorda completamente com a teoria $\mathrm{X}$ e nem elogiar quem concorda inteiramente com a teoria Y. Porém, o indivíduo precisa analisar as atitudes que baseiam seus motivos e comportamentos.

\section{Teoria das Necessidades Adquiridas de David Mcclelland}

David McClelland foi um dos mais notáveis autores na área da motivação humana. Ele foi um psicólogo estadunidense, conhecido pela teoria das necessidades adquiridas. Nasceu em 1917, em Mount Vernon, Nova York. Formou-se na Wesleyan University, fazendo depois mestrado em Psicologia pela University of Missouri e doutorado em Psicologia Experimental pela Yale University. Antes de ingressar como professor na Harvard University, onde trabalhou por 30 anos com pesquisas, lecionou no Connecticut College e na Wesleyan University. A teoria das necessidades adquiridas foi apresentada no seu livro "The achieving society" na década de 1960.

Existem três fatores diferentes responsáveis por motivar os diferentes comportamentos humanos. Esses fatores são: afiliação, poder e realização. A necessidade de afiliação está associada ao fato do indivíduo querer manter amizades e relacionamentos com outras pessoas. Sendo seguida pela necessidade de poder que se expressa no desejo de controlar, influenciar e liderar outros indivíduos. Por fim, vem a necessidade de realização que está relacionada ao desejo da pessoa de crescer profissionalmente, adquirindo mais responsabilidades e importância no trabalho (MCCLELLAND, 1961).

Para Bergamini (2008), as necessidades são adquiridas socialmente, pois o indivíduo pode aprender novas necessidades ao decorrer do tempo, ou seja, ele desenvolve as suas necessidades durante a vida por meio de experiências adquiridas em seu meio social.

As necessidades de afiliação, poder e realização são adquiridas socialmente, onde as de poder têm relação com prestígio, status social e capacidade de influência sobre as outras pessoas. Já as de afiliação têm relação com a necessidade de ser amado e respeitado pelos colegas de trabalho. Enquanto que, a de realização está relacionada com a necessidade que o indivíduo tem de se sentir realizado com as suas conquistas tanto pessoais, quanto profissionais (VERGARA, 2005b).

De acordo com Robbins et al. (2013), a teoria das necessidades adquiridas se baseia na ideia que um indivíduo está na procura de suprir três necessidades dominantes: realização, poder e afiliação. A necessidade de realização está relacionada à vontade de ter sucesso e superar os demais. A necessidade de 
poder tem relação com o desejo de influenciar as pessoas. E a afiliação refere-se à necessidade de ter relações afetivas com os outros.

\section{Teoria Bifatorial de Frederick Herzberg}

Frederick Herzberg foi um psicólogo estadunidense que elaborou a teoria dos dois fatores. Ele foi um dos autores mais influentes com relação à temática da motivação humana. Nasceu em 1923 em Lynn, Massachusetts. Formou-se no City College of New York em 1946. Posteriormente, fez mestrado em Ciências e Saúde Pública pela University of Pittsburgh e doutorado em Terapia de Choque Elétrico pela mesma Instituição. A sua publicação mais conhecida é a "One more time, how do you motivate employees" na Harvard Business Review, sendo este apresentado a teoria bifatorial. Ele trabalhou na University of Utah com pesquisas sobre as organizações e também prestou consultoria para diversas empresas.

Com o objetivo de conceituar a motivação, Herzberg (1968), trouxe a diferença entre os fatores motivacionais e os higiênicos. Os fatores motivacionais são internos ao colaborador, podendo ser considerados como fatores motivacionais: o reconhecimento, a realização, o trabalho em si, o crescimento e a responsabilidade. Já os fatores higiênicos são externos ao colaborador, pois são dados a ele para exercer suas funções, como o salário, a segurança, as condições de trabalho, os benefícios e as políticas organizacionais.

Segundo Griffin et al. (2006), Herzberg descobriu que fatores completamente diferentes tinham relação com emoções boas e ruins no ambiente de trabalho. Uma pessoa que ganha um salário insuficiente irá, logicamente, se sentir insatisfeita, porém, caso passe a ganhar um salário suficiente, não necessariamente, irá sentir-se satisfeita.

Além disso, conforme Caravantes (1998), Herzberg determinou que os fatores que influenciam a satisfação eram distintos dos que tinham influência sobre a insatisfação. Dessa forma, o contrário de satisfação é não-satisfação e o oposto de insatisfação será não-insatisfação. Segundo Chiavenato (2000), os fatores motivacionais estão relacionados ao conteúdo do cargo que o colaborador exerce e as atividades desafiadoras. Já os fatores higiênicos têm relação com o salário, o ambiente de trabalho e o relacionamento com supervisores e colegas.

De acordo com Silva et al. (2015), Herzberg buscou analisar os comportamentos e motivações presentes nos colaboradores, identificando os fatores que influenciam no nível de satisfação dos mesmos. A partir de sua pesquisa, foi desenvolvida a teoria bifatorial que determinam as variáveis que trazem satisfação e insatisfação aos funcionários no âmbito organizacional. Assim, a organização saberá quais ações devem implementar com o intuito de elevar a satisfação dos seus empregados.

\section{Teoria da Expectância de Victor Vroom}

Victor Vroom é um psicólogo canadense conhecido pela elaboração da teoria da expectância. Ele nasceu em 1932 em Montreal, Quebec. Formou-se em Psicologia pela McGill University, fazendo seu mestrado na mesma Instituição e o doutorado pela University of Michigan. Entre os seus livros, pode-se 
destacar: Work and Motivation, onde apresentou a teoria da expectância, Leadership and decision making e New leadership. Em 1972, ele foi nomeado presidente do departamento de ciências administrativas e diretor associado da instituição para estudos sociais e políticas na Yale School of Management. Vroom também foi consultor para diversas empresas como a General Electric e a American Express.

A teoria da expectância de Victor Vroom (1964) é um estudo que qualifica as relações entre diversas variáveis, ajudando a definir o comportamento do colaborador no ambiente de trabalho. Essa teoria defende que exista uma relação direta entre o desempenho do indivíduo e a recompensa conquistada, ou seja, ele era incentivado a se esforçar para ter um desempenho positivo, pois pensava que iria resultar em uma determinada recompensa que deixaria suas necessidades satisfeitas (MELLO et al., 2007).

A teoria da expectância é uma das principais dentro do campo de estudo da motivação humana. Além disso, segundo Robbins (2008), a motivação do colaborador em produzir tem relação direta com os objetivos pessoais e os esforços necessários para atingi-los.

A teoria da expectância é como uma função de três partes, onde a expectativa ocorre na ocasião que o desempenho positivo irá depender do esforço empregado pelo indivíduo, enquanto que a valência acontece quando esse esforço utilizado dependerá da valorização que o indivíduo colocará na recompensa. E, por último, a instrumentalidade é percebida no momento em que a motivação para se esforçar se condiciona à expectativa canalizada no esforço que terá impacto na recompensa (MAXIMIANO, 2010).

De acordo com Limongi-França (2002), a teoria da expectância analisa a pessoa como um ser que tem necessidades, valores e princípios agindo com esforço ideal e a expectativa de cumprir com os seus objetivos. Logo, o indivíduo irá agir de modo a satisfazer suas necessidades.

Segundo Chiavenato (2002), um dos principais fatores motivacionais para o colaborador produzir com eficiência são os objetivos pessoais, ou seja, o nível da motivação irá depender da expectativa que o indivíduo tem de realizar algo que o ajude na busca do cumprimento de determinado objetivo.

\section{Teoria da Equidade de Stacy Adams}

Para Spector (2010), a teoria da equidade defende que os colaboradores são incentivados ao sentirem que atingiram uma situação de igualdade no relacionamento com os colegas de trabalho dentro da organização. Logo, segundo a teoria, o colaborador se sente satisfeito em trabalhar em um local que tenha um relacionamento igualitário entre todos.

A equidade somente existe quando a proporção entre esforço empregado e resultado conquistado é igual entre todos os colaboradores da organização, ou seja, quando ocorre o contrário, caracteriza-se como desigualdade. Logo, é importante que a organização busque sempre recompensar os seus colaboradores com base nos resultados e desempenhos alcançados pelos mesmos, de modo igual e justo (HITT, 2007)

De acordo com Adams (1965), a iniquidade é caracterizada quando o indivíduo percebe uma relação desigual existente entre o esforço empregado e os resultados alcançados dos colaboradores. Assim, a iniquidade traz como consequência, a insatisfação por parte do colaborador, pois ele sente que seu desempenho não está sendo devidamente valorizado pela organização. 
Segundo Silva (2001), quando o colaborador percebe que está em uma relação injusta no ambiente de trabalho, busca-se reduzir seus esforços, diminuindo o nível de qualidade do trabalho ou começa a reclamar da remuneração recebida de modo injusto, onde em alguns casos mais extremos, o colaborador se sente tão insatisfeito que prefere pedir demissão.

\section{Educação Superior no Brasil}

De acordo com Chauí (2003), a universidade é a instituição que está associada ao contexto social do local onde está inserida a mesma. É dentro da instituição de ensino superior que se cria diversos posicionamentos, questionamentos, ações que mostram a diversidade presente dentro da instituição.

Dessa forma, de acordo com o art. 43 da Lei de Diretrizes e Bases da Educação Nacional, de 20 de dezembro de 1996 (BRASIL, 1996), a educação superior tem as seguintes finalidades: estimular a criação cultural, o espírito científico e o pensamento reflexivo; formar profissionais nas diferentes áreas do conhecimento; incentivar à pesquisa e a investigação científica, com o intuito de desenvolver a ciência e a tecnologia; promover a divulgação de conhecimentos culturais, científicos e técnicos; promover o desejo de aperfeiçoamento cultural e profissional; estimular o conhecimento dos problemas do mundo contemporâneo; promover a extensão, aberta à participação da população e atuar no aprimoramento da educação básica por meio da formação e capacitação de profissionais.

Nos primeiros anos do século XXI, houve uma expansão na oferta de educação superior no Brasil, isso aconteceu por meio da "implementação de medidas provisórias, projetos de lei, leis e decretos, viabilizando o aumento do número de matrículas no ensino superior nas IES e manteve-se o crescimento de IES privadas." Portanto, houve a criação de políticas públicas com o objetivo de desenvolver o ensino superior no Brasil (AGAPITO, 2017).

Além disso, para Mancebo et al. (2015), a expansão da educação superior aconteceu no governo de Luiz Inácio Lula da Silva com a criação do Programa de Apoio a Planos de Reestruturação e Expansão das Universidades Federais (Reuni), que visava aumentar a quantidade de discentes nas universidades federais e também aumentar o número de alunos por professor em sala de aula.

Segundo Chaves et al. (2016), a criação do Programa Universidade para Todos (ProUni) e do Fundo de Financiamento Estudantil do Ensino Superior (FIES) contribuiu para o aumento das matrículas nas instituições privadas. Assim, viabilizando a expansão do ensino superior por meio das IES privadas.

Com isso, no Brasil, atualmente, existem 2.608 Instituições de Ensino Superior - IES, sendo divididas em 302 IES públicas e 2.306 IES privadas. Dentre as Instituições de Ensino Superior de caráter público, existem 110 federais, 132 estaduais e 60 municipais. No Brasil são ofertados 40.427 cursos de graduação, tendo aproximadamente 8.6 milhões de matrículas nos cursos de graduação. As IES privadas têm $75,8 \%$ de participação na quantidade total de matrículas de graduação, enquanto as IES públicas têm somente uma participação de $24,2 \%$ das matrículas (INEP, 2019). 


\section{METODOLOGIA}

O presente estudo tratou-se de uma pesquisa de natureza básica, que para Gerhardt et al. (2009), possibilita a geração de novos conhecimentos sem a necessidade de aplicação prática. Utilizou-se a abordagem qualitativa, que segundo Rodrigues et al. (2006), não utiliza procedimentos estatísticos e busca representar aspectos relacionados ao comportamento, opiniões e atitudes dos indivíduos. A pesquisa teve objetivo exploratório, que de acordo com Gil (2002), a pesquisa exploratória se caracteriza por proporcionar um maior conhecimento acerca de determinado problema que o pesquisador esteja investigando.

A pesquisa é do tipo bibliográfica que segundo Marconi et al. (2003), utiliza-se de fontes secundárias, ou seja, se baseia em informações de outros trabalhos que já foram publicados. Pode-se obter informações de jornais, livros, revistas, teses, dissertações, monografias, etc. O objetivo desse tipo de pesquisa é fazer o pesquisador ter contato com tudo que já foi escrito e publicado, anteriormente, sobre um determinado tema.

Na pesquisa foi empregado o processo metodológico da revisão sistemática de literatura, que segundo Galvão et al. (2019) é uma modalidade de pesquisa que segue critérios específicos, buscando entender e dar uma lógica a estudos, verificando o que funciona em um determinado contexto. Dessa forma, a pesquisa baseou-se em trabalhos científicos publicados nas plataformas Google Acadêmico e Scientific Electronic Library Online - SciELO. Para a seleção dos trabalhos científicos, foram utilizados os descritores: 'motivação no trabalho', 'colaboradores' e 'instituições de ensino superior'.

A pesquisa teve como critério de inclusão: (01) a seleção de artigos publicados em eventos, periódicos científicos e trabalhos de conclusão de curso; (02) publicados entre os anos de 2016 a 2020; (03) artigos publicados em língua portuguesa; (04) artigos publicados em periódicos brasileiros. Foram critérios de exclusão: (01) trabalhos que não estão alinhados com o problema do estudo; (02) trabalhos de língua estrangeira; (03) artigos duplicados. Inseridos os critérios de inclusão e exclusão no processo de pesquisa foram encontrados 21 artigos empregando os critérios expostos, foram excluídos 13, sendo 8 elegíveis para análise.

O estudo utilizou-se como instrumento de organização de dados a apresentação gráfica em formato de um quadro, sendo disposta dos seguintes tópicos: ano de publicação; autores/as; revista e/ou evento científico; IES; título e teorias motivacionais. O método de análise de dados utilizado nessa pesquisa foi a análise de discurso, que segundo Mozzato et al. (2011), é uma técnica que estuda as relações entre o discurso e a realidade, observando como os textos são produzidos, transportando o significado por intermédio de processos sociais.

\section{RESULTADOS E DISCUSSÃO}

Neste tópico trouxe os resultados referentes aos trabalhos científicos analisados, que discutiam sobre a motivação no âmbito das Instituições de Ensino Superior. A seleção desses trabalhos teve como intenção compreender os fatores que influenciam na motivação dos colaboradores para trabalhar dentro das organizações de ensino superior. Logo a seguir, tem-se o quadro: Trabalhos científicos que tem como 
temática a motivação nas IES, que explicita os trabalhos científicos encontrados que tratam sobre a temática pesquisada.

Quadro 1: Trabalhos científicos que tem como temática a motivação nas IES.

\begin{tabular}{|c|c|c|c|c|c|c|}
\hline Id. & $\begin{array}{c}\text { Ano de } \\
\text { publicação }\end{array}$ & Autor(es) & $\begin{array}{c}\text { Revista e/ou } \\
\text { Evento Científico }\end{array}$ & IES & Título & $\begin{array}{c}\text { Teorias } \\
\text { Motivacionais }\end{array}$ \\
\hline 1 & 2016 & $\begin{array}{l}\text { Patrícia Lira Barros; José } \\
\text { Airton Mendonça de } \\
\text { Melo }\end{array}$ & $\begin{array}{l}\text { Universitas: gestão } \\
\text { e TI }\end{array}$ & $\begin{array}{l}\text { Faculdade } \\
\text { Projeção }\end{array}$ & $\begin{array}{l}\text { Motivação e clima } \\
\text { organizacional: um estudo } \\
\text { de caso em uma instituição } \\
\text { de ensino superior }\end{array}$ & $\begin{array}{l}\text { Teoria da } \\
\text { pirâmide das } \\
\text { necessidades; } \\
\text { Teoria X e Y de } \\
\text { McGregor; } \\
\text { Teoria bifatorial } \\
\text { de Herzberg; } \\
\text { Teoria da } \\
\text { Expectância de } \\
\text { Vroom }\end{array}$ \\
\hline 2 & 2017 & $\begin{array}{l}\text { Hariane Jackeline } \\
\text { Rodrigues Silva; } \\
\text { Leandro Frederico da } \\
\text { Silva }\end{array}$ & $\begin{array}{l}\text { Revista de } \\
\text { Magistro de } \\
\text { Filosofia }\end{array}$ & $\begin{array}{l}\text { Faculdade } \\
\text { Católica de } \\
\text { Anápolis }\end{array}$ & $\begin{array}{l}\text { O endomarketing como } \\
\text { ferramenta ativa na gestão } \\
\text { de pessoas de uma } \\
\text { instituição de ensino } \\
\text { superior de Anápolis }\end{array}$ & $\begin{array}{l}\text { Este artigo não } \\
\text { abordou as } \\
\text { teorias da } \\
\text { motivação }\end{array}$ \\
\hline 3 & 2017 & $\begin{array}{l}\text { Luiz Cesar dos Santos } \\
\text { Lima; Veronica Leuch; } \\
\text { Bruno Roberto Buss }\end{array}$ & Revista Espacios & $\begin{array}{l}\text { Faculdade } \\
\text { Arapoti - FATI }\end{array}$ & $\begin{array}{l}\text { A importância da pesquisa } \\
\text { de clima organizacional para } \\
\text { análise do nível de } \\
\text { satisfação dos } \\
\text { colaboradores e da } \\
\text { estrutura organizacional }\end{array}$ & $\begin{array}{l}\text { Este artigo não } \\
\text { abordou as } \\
\text { teorias da } \\
\text { motivação }\end{array}$ \\
\hline 4 & 2018 & $\begin{array}{l}\text { Amanda de Melo Alves } \\
\text { de Oliveira; Alyne Bento } \\
\text { de Lima Brianezzi }\end{array}$ & $\begin{array}{l}\text { Revista Científica } \\
\text { Semana Acadêmica }\end{array}$ & $\begin{array}{l}\text { Centro } \\
\text { Universitário } \\
\text { Adventista de São } \\
\text { Paulo }\end{array}$ & $\begin{array}{l}\text { Estratégia de marketing } \\
\text { interno em instituições de } \\
\text { ensino superior: ótica do } \\
\text { docente }\end{array}$ & $\begin{array}{l}\text { Este artigo não } \\
\text { abordou as } \\
\text { teorias da } \\
\text { motivação }\end{array}$ \\
\hline 5 & 2018 & $\begin{array}{l}\text { Eliane Salete Filippim; } \\
\text { Silvio Santos Júnior; } \\
\text { Lígia Krühs Zulian; Fábio } \\
\text { Lazzarotti }\end{array}$ & Revista Reuna & $\begin{array}{l}\text { Universidade do } \\
\text { Oeste de Santa } \\
\text { Catarina }\end{array}$ & $\begin{array}{l}\text { Motivação e retenção de } \\
\text { docentes em instituição de } \\
\text { ensino superior }\end{array}$ & $\begin{array}{l}\text { Teoria bifatorial } \\
\text { de Herzberg }\end{array}$ \\
\hline 6 & 2018 & $\begin{array}{l}\text { Kleber Rodrigo dos } \\
\text { Anjos; Fernando } \\
\text { Clemente Cunha Bastos; } \\
\text { Larisa Hemkemeier } \\
\text { Webber de Melo; Mara } \\
\text { Regina Balena; Aretuza } \\
\text { Balardim Sain; Altir } \\
\text { Webber de Mello Neto }\end{array}$ & $\begin{array}{l}\text { XVIII Colóquio } \\
\text { Internacional de } \\
\text { Gestão } \\
\text { Universitária }\end{array}$ & $\begin{array}{l}\text { Faculdade } \\
\text { Municipal de } \\
\text { Palhoça }\end{array}$ & $\begin{array}{l}\text { Análise da percepção do } \\
\text { clima organizacional em } \\
\text { uma instituição de ensino } \\
\text { superior }\end{array}$ & $\begin{array}{l}\text { Teoria da } \\
\text { pirâmide das } \\
\text { necessidades de } \\
\text { Maslow; } \\
\text { Teoria bifatorial } \\
\text { de Herzberg }\end{array}$ \\
\hline 7 & 2019 & $\begin{array}{l}\text { Greice Marta } \\
\text { Spananberg Monteiro }\end{array}$ & $\begin{array}{l}\text { Biblioteca Digital } \\
\text { da Universidade } \\
\text { Regional do } \\
\text { Noroeste do } \\
\text { Estado do Rio } \\
\text { Grande do Sul } \\
\end{array}$ & $\begin{array}{l}\text { Universidade } \\
\text { Regional do } \\
\text { Nordeste do } \\
\text { Estado do Rio } \\
\text { Grande do Sul }\end{array}$ & $\begin{array}{l}\text { A influência das variáveis } \\
\text { que compõem o clima } \\
\text { organizacional no } \\
\text { comprometimento das } \\
\text { equipes de trabalho: o } \\
\text { estudo em uma IES-RS }\end{array}$ & $\begin{array}{l}\text { Este artigo não } \\
\text { abordou as } \\
\text { teorias da } \\
\text { motivação }\end{array}$ \\
\hline 8 & 2020 & $\begin{array}{l}\text { Sarah Tiburtino } \\
\text { Moreira; Rodrigo } \\
\text { Randow de Freitas }\end{array}$ & $\begin{array}{l}\text { Brazilian Journal of } \\
\text { Production } \\
\text { Engineering }\end{array}$ & $\begin{array}{l}\text { Universidade } \\
\text { Federal do } \\
\text { Espírito Santo }\end{array}$ & $\begin{array}{l}\text { Evidências de efeito da } \\
\text { satisfação e motivacional } \\
\text { em uma instituição pública } \\
\text { federal de ensino superior }\end{array}$ & $\begin{array}{l}\text { Teoria da } \\
\text { pirâmide das } \\
\text { necessidades de } \\
\text { Maslow; } \\
\text { Teoria bifatorial } \\
\text { de Herzberg; } \\
\text { Teoria das } \\
\text { necessidades } \\
\text { adquiridas de } \\
\text { McClelland } \\
\text { Teoria de Alderfer }\end{array}$ \\
\hline
\end{tabular}

Com relação às pessoas no ambiente de trabalho, Barros et al. (2016) no artigo intitulado: Motivação e clima organizacional: um estudo de caso em uma instituição de ensino superior do $D F$, perceberam que a maioria dos colaboradores eram orientados de forma clara e objetiva no processo de execução de suas funções no trabalho. Além disso, a maioria dos funcionários se sentem reconhecidos pela organização quando desenvolvem suas atividades de modo eficiente. Também é importante dizer que as condições de 
trabalho nesta IES é um fator de satisfação para os funcionários, sendo essencial para a qualidade do ambiente organizacional. Nesse estudo também é visto que a maioria dos colaboradores desconheciam a existência de conflitos entre os trabalhadores e quando perguntados sobre os motivos de trabalhar na IES pesquisada, a maioria respondeu por causa do salário e do ambiente de trabalho.

De acordo com Silva et al. (2017) em seu artigo intitulado: $O$ endomarketing como ferramenta ativa na gestão de pessoas de uma instituição de ensino superior, analisou que a maioria dos colaboradores da IES pesquisada tem como fatores motivacionais para se trabalhar é a realização profissional e a busca por estabilidade. Além disso, o autor cita que é importante saber quais são os colaboradores que estão motivados e os que não estão motivados, pois um funcionário que esteja desmotivado pode influenciar no ambiente de trabalho de modo negativo. Portanto, é necessário criar benefícios que satisfaçam todos os colaboradores da organização. Com relação a comunicação interna na IES, foi respondido, pela maioria, que as informações são claras e acessíveis a todos os colaboradores. Também foi perguntado sobre a capacidade de comunicação do líder imediato, verificou-se que a maioria dos colaboradores considera muito boa a capacidade de comunicar do seu líder.

Para Lima et al. (2017) em seu artigo intitulado: A Importância da pesquisa de clima organizacional para análise do nível de satisfação dos colaboradores e da estrutura organizacional, os colaboradores, em sua maioria, têm uma identificação com a empresa, porém, foi sugerido pelos mesmos que a empresa promovesse reuniões entre a diretoria e os setores da organização para discutir as ações que irá ocorrer durante o ano e também promover eventos de integração entre os departamentos. Além do mais, a maioria dos colaboradores concordam que exista uma relação positiva entre os subordinados e os líderes imediatos. Entretanto, os funcionários tiveram como sugestão de melhoria que a empresa promova treinamentos de como dar e receber feedback para os líderes e buscar definir com clareza quais são as funções de cada chefe dentro da organização. Com relação ao reconhecimento, os funcionários acreditam que sejam reconhecidos pelo seu trabalho na empresa, no entanto, foi sugerido pelos colaboradores que os líderes busquem elogiar mais os desempenhos considerados acima da média.

Oliveira et al. (2018) no artigo intitulado: Estratégia de marketing interno em instituições de ensino superior, analisou que os colaboradores percebem que a IES oferece cursos, treinamentos e palestras para o desenvolvimento dos mesmos. Além disso, a maioria dos docentes acreditam que o modo como o coordenador lidera, influência na motivação e desempenho no ambiente de trabalho, esse aspecto é importante, pois a participação do líder leva o liderado a se sentir mais seguro para cumprir com as suas atividades, trazendo resultados satisfatórios para a instituição. Também é importante destacar que para a maioria dos docentes, eles recebem motivação e um claro feedback por parte do coordenador. Portanto, pode-se dizer que a preocupação em desenvolver o pessoal e dar um feedback eficiente são determinantes para a motivação dos colaboradores, impactando diretamente no desempenho deles.

Analisando as motivações para se trabalhar em uma IES, Filippim et al. (2018) em seu artigo intitulado: Motivação e retenção de docentes em Instituição de ensino superior comunitária, pôde verificar que um ambiente organizacional agradável e a possibilidade de fazer pesquisas científicas são fatores 
motivacionais importantes para os colaboradores. Com relação aos fatores motivacionais para permanecer na IES, a maioria dos docentes considera o trabalho realizado como muito significativo. Variáveis que motivam consideradas importantes para os colaboradores, pode-se destacar a autonomia no desenvolvimento das funções, a flexibilidade com relação aos horários de trabalho, as relações interpessoais com os colegas e com os superiores imediatos que são satisfatórias.

Segundo Anjos et al. (2018) em seu artigo intitulado: Análise da percepção do clima organizacional em uma instituição de ensino superior, os colaboradores se sentem satisfeitos com o clima organizacional dentro do ambiente de trabalho, sendo importante salientar que existe satisfação nas relações entre os colaboradores. No que diz respeito ao tratamento que os colaboradores recebem, é analisado que existe nessa IES uma igualdade de tratamento. Além disso, foi estudado o nível de participação dos colaboradores nas tomadas de decisão junto com o líder, assim, resultou-se que os colaboradores sentem que podem contribuir com o líder nas decisões. Quando se indagou sobre o papel da liderança dentro da IES, a maioria dos colaboradores se sentem satisfeitos com o desempenho do líder. Também foi perguntado aos funcionários sobre a percepção deles diante dos investimentos feitos em treinamentos e com os subsídios oferecidos para o crescimento profissional, foi visto que a maioria dos colaboradores estão satisfeitos com a organização mediante a esses aspectos.

Em relação aos fatores motivacionais presentes no trabalho, Monteiro (2019) em seu artigo intitulado: A influência das variáveis que compõem o clima organizacional no comprometimento das equipes de trabalho: o estudo em uma IES-RS, verificou que os colaboradores se sentem satisfeitos com o ambiente organizacional, com a remuneração recebida e com os benefícios que são oferecidos pela IES. Além do mais, foi analisado que a relação entre gestores e os colaboradores é considerada positiva, existindo uma relação de respeito e tendo um grau de feedback satisfatório. Com relação aos treinamentos, é percebido que é suficiente para contribuir no desenvolvimento de um bom desempenho e possibilita o crescimento pessoal para os funcionários. Também, é importante destacar que a maioria dos colaboradores sentem que existe a possibilidade de ascensão dentro da organização. Portanto, as variáveis apresentadas trazem um nível elevado de satisfação para os colaboradores da IES, contribuindo para uma maior produtividade.

Com respeito aos fatores motivacionais, segundo Moreira et al. (2020) em seu artigo intitulado: Evidências de efeitos da satisfação e motivação em uma instituição pública federal de ensino superior, a IES pesquisada não possui um planejamento de capacitação e treinamento para os seus colaboradores, quando existe algum tipo de treinamento é feito de modo online. Quando se refere ao ambiente de trabalho e aos relacionamentos com os outros colaboradores é visto que existe uma relativa satisfação por parte deles. Além disso, por causa da IES ser pública, a estabilidade é considerada um fator motivacional muito importante para as pessoas que trabalham na instituição. Porém, existe um nível de insatisfação por parte dos funcionários por não existir uma integração adequada entre os colegas de trabalho. Outro fator que traz a insatisfação por parte dos colaboradores é o fato de não existir um departamento de recursos humanos no campus da IES. 


\section{CONCLUSÕES}

Percebe-se que a motivação é responsável por impulsionar comportamentos específicos nos colaboradores, ou seja, a motivação faz com que a pessoa seja mais participativa no ambiente de trabalho, desenvolvendo as funções do seu cargo da melhor maneira. Porém, a falta de motivação ocasiona em consequências negativas, pois o funcionário irá diminuir a sua produtividade, irá criar conflitos com os seus colegas de trabalho, assim, prejudicando o clima organizacional da empresa como um todo. Deste modo, a falta de motivação de um colaborador pode afetar na produtividade de um departamento ou até mesmo de toda a organização. Logo, cria-se a necessidade por parte dos gestores e líderes de estudar sobre a motivação de um colaborador no âmbito organizacional, objetivando manter todos eles motivados e satisfeitos com o seu trabalho.

Dessa forma, durante os anos, diversos autores buscaram estudar acerca da temática proposta nesse artigo, criando-se as teorias da motivação. Nesta presente pesquisa, foram apresentadas 6 teorias sobre a motivação, a saber: a pirâmide das necessidades de Abraham Maslow, que defende que existem cinco categorias principais que influenciam na satisfação do indivíduo que são os fatores fisiológicos, de segurança, sociais, estima e autorrealização. É importante dizer que o indivíduo somente muda de fator motivacional quando o fator atual está completamente satisfeito, criando-se a ideia de pirâmide. Outra teoria estudada foi a teoria $\mathrm{X}$ e $\mathrm{Y}$ de Douglas McGregor, que de acordo com essa teoria existem 2 maneiras de analisar os funcionários, a primeira é a teoria $\mathrm{X}$, que descreve o colaborador como um indivíduo preguiçoso e que trabalha pensando somente no salário. Porém, a teoria $Y$ descreve a pessoa como um indivíduo que é motivado e tem muita proatividade.

A próxima teoria estudada foi às necessidades adquiridas de David McClelland, que defende que existem três fatores que motivam o indivíduo, que são afiliação, poder e realização. Todos esses fatores, segundo a teoria, são adquiridos com o tempo, ou seja, as pessoas não nascem com essas necessidades. Outra teoria é a bifatorial de Frederick Herzberg, que explica que existem os fatores motivacionais, que são os fatores internos ao colaborador, e os fatores higiênicos, que são os fatores externos ao colaborador, de acordo com essa tese, os fatores motivacionais, obviamente, motiva o indivíduo, enquanto, os fatores higiênicos evitam a desmotivação. Também tem a teoria da expectância de Victor Vroom, que explica que a motivação está na expectativa que o funcionário tem diante da possível recompensa conquistada. Por fim, tem a teoria da equidade de Stacy Adams, que defende que o indivíduo se sente motivado quando está num ambiente onde existe igualdade entre ele e seus colegas de trabalho.

Acerca das teorias da motivação encontrados nos artigos apresentados no tópico de resultados e discussões, pôde-se analisar que 4 artigos apresentaram as seguintes teorias: teoria da hierarquia das necessidades de Abraham Maslow; teoria X e Y de Douglas McGregor; teoria dos dois fatores de Frederick Herzberg; teoria da expectância de Victor Vroom e teoria ERG de Clayton Alderfer, sendo essa teoria não apresentada no tópico da fundamentação teórica. Referente aos outros 4 artigos, esses não fizeram nenhuma menção às teorias da motivação, sendo encontrados nesses, uma definição acerca da motivação 
mais ampla sem discorrer sobre nenhuma teoria. Diante das teorias observadas nos artigos, pode-se destacar que novas teorias sobre motivação estão surgindo como a teoria ERG de Alderfer.

Com relação aos resultados obtidos nesse estudo, pode-se concluir que existem diversos fatores que motivam os colaboradores dentro das instituições de ensino superior, podendo-se inferir frente a revisão de literatura como fatores motivacionais presentes nas IES: a oferta de treinamentos, cursos, palestras e bolsas de estudos são ações promovidas pelas instituições que contribui para a satisfação dos funcionários, pois eles se sentem importantes e valorizados como profissionais na organização. Outro fator importante é a comunicação e o feedback claros, pois esses aspectos influenciam nos relacionamentos entre os colaboradores com os seus líderes e contribui para uma maior produtividade. Assim, uma comunicação eficiente colabora para a diminuição dos conflitos existentes nas organizações, assim, criando um clima positivo e propenso a resultados satisfatórios, suprindo as necessidades individuais e organizacionais

Também foi percebido que os colaboradores se sentem mais motivados quando têm a percepção de que são realizados profissionalmente, para isso, é importante que os líderes busquem reconhecer os seus colaboradores que têm alta performance. É visto que os colaboradores valorizam os salários recebidos e os benefícios ofertados pelas IES. Também, foi verificado que os colaboradores se sentem mais motivados quando os líderes dão mais oportunidades a eles para participar das tomadas de decisão, pois verifica-se que nas instituições que têm esse tipo de liderança, os colaboradores se sentem mais satisfeitos com o papel dos líderes na instituição, além de julgarem serem mais capazes de desenvolver suas atividades da melhor maneira.

Portanto, com base nos estudos encontrados que discutam sobre a motivação de colaboradores nas IES, foi percebido que os mesmos se sentem motivados no seu trabalho. Indica-se a necessidade de ampliar as pesquisas sobre a motivação em ambientes de Instituições de Ensino Superior.

\section{REFERÊNCIAS}

ADAMS, J. S.. Inequity in social exchange. In: BERKOWITZ, L. Advances inexperimental social psychology. New York: Academic Press, 1965. p.267-300.

ANJOS, K. R.; BASTOS, F. C. C.; MELLO, L. H. W.; BALENA, M. R.; SAIN, A. B.; MELLO NETO, A. W.. Análise da percepção do clima organizacional em uma instituição de ensino superior. In: COLÓQUIO INTERNACIONAL DE GESTÃO UNIVERSITÁRIA, 18. Anais. Florianópolis: Repositório Institucional da Universidade Federal de Santa Catarina, 2018.

ANDRADE, R. O. B. D.; AMBONI, N.. Teoria geral da administração. Rio de Janeiro: Elsevier, 2009.

AGAPITO, A. P. F.. Ensino superior no Brasil: expansão e mercantilização na contemporaneidade. Temporalis, v.16, n.32, p.123-140, 2017.

BARROS, P. L.; MELO, J. A. M.. Motivação e clima organizacional: um estudo de caso em uma Instituição Pública Federal de Ensino Superior do DF. Universitas Gestão e TI, Brasília, v.6, n.2, p.1-15, 2016.

BERGAMINI, C. W.. Motivação nas Organizações. 5 ed. São
Paulo: Atlas, 2008.

BOCK, A. M. B.; FURTAdO, O.; TEIXEIRA, M. L. D.. Psicologias: uma introdução ao estudo de psicologia. 13 ed. São Paulo: Saraiva, 1999.

BRASIL. Lei n. 9.394, de 20 de dezembro de 1996. Estabelece as Diretrizes e Bases da Educação Nacional. Brasília: DOU, 1996.

CARAVANTES, G. R.. Teoria Geral da Administração: Pensando e Fazendo. 4 ed. Porto Alegre: AGE LTDA, 1998.

CARVALHO, J. F.; MARTINS, E. P. T.; LÚCIO, L.; PAPANDRÉA, P. J.. Qualidade de vida no trabalho e fatores motivacionais dos colaboradores nas organizações. Educação em Foco, n.7, 2013.

CHAUÍ, M.. A universidade pública sob nova perspectiva. Revista Brasileira de Educação. Rio de Janeiro, v.24, p.5-15, 2003.

CHAVES, V. L. J.; AMARAL, N. C.. Política de expansão da educação superior no Brasil: o ProUni e o FIES como 
financiadores do setor privado. Educação em Revista. v.32, n.4, p.49-72, 2016

CHIAVENATO, I.. Introdução à Teoria Geral da

Administração; edição compacta; $2^{a}$ ed. revista e atualizada. Rio de Janeiro: Campus, 2000.

CHIAVENATO, I.. Recursos humanos. 7 ed. São Paulo: Atlas, 2002.

CHIAVENATO, I.. Administração: teoria, processo e prática. 4 ed. Rio de Janeiro: Elsevier, 2007.

CHIAVENATO, I.. Administração de Recursos Humanos: Fundamentos Básicos. 7 ed. Barueri: Manole, 2010.

FILIPPIM, E. S.; SANTOS JÚNIOR, S.; ZULIAN, L. K.; LAZZAROTTI, F.. Motivação e retenção de docentes em Instituição de Ensino Superior comunitária. REUNA, Belo Horizonte, v.23, n.1, p.54-74, 2018.

GALVÃO, M. C. B.; RICARTE, I. L. M.. Revisão sistemática da literatura: conceituação, produção e publicação. Logeion: Filosofia da Informação, v.6, n.1, p.57-73, 2019.

GIAUQUE, D.; RITZ, A.; VARONE, F.; ANDERFUHREN-BIGET, S.. Resigned but satisfied: the negative impact of public service motivation and red tape on work satisfaction. Public Administration, v.90, n.1, p.175-193, 2012.

GERHARDT, T. E.; SILVEIRA, D. T.. Métodos de Pesquisa. Porto Alegre: UFRGS, 2009

GIL, A. C.. Como elaborar projetos de pesquisa. 4 ed. São Paulo: Atlas, 2002

GRIFFIN, R. W.; MOORHEAD, G.. Fundamentos do Comportamento Organizacional. São Paulo: Ática, 2006.

HENCKE, F. M.; FRAGA, R. M.. Os fatores motivacionais no ambiente de trabalho: estudo de caso em uma empresa calçadista no Vale do Paranhana/RS. Revista de administração de empresas eletrônicas, n.6, 2017.

HERZBERG, F. I.. One more time: how do you motivate employees?. Harvard Business Review, Boston, v.46, n.1, p.53-62, 1968.

HITT, M. A.. Comportamento organizacional: uma abordagem estratégica. Rio de Janeiro: LTC, 2007.

LIMA, L. C. S.; LEUCH, V.; BUSS, B. R.. A importância da pesquisa de clima organizacional para análise do nível de satisfação dos colaboradores e da estrutura organizacional. Revista Espacios, v.38, n.28, 2017.

LIMONGI-FRANÇA, A. C.. As pessoas nas organizações. São Paulo: Gente, 2002.

LOCKE, E. A.. What is job satisfaction?. Organizational Behaviour Human Performance, v.4, n.4, p.309-336, 1969.

INEP. Instituto Nacional de Estudos e Pesquisas Educacionais Anísio Teixeira. Censo da Educação Superior. Brasília: INEP, 2019.

MANCEBO, D.; VALE, A. A.; MARTINS, T. B.. Políticas de expansão da educação superior no Brasil 1995-2010. Revista Brasileira de Educação, v.20, n.60, 2015.

MARCONI, M. A.; LAKATOS, E. M.. Fundamentos de metodologia científica. 5 ed. São Paulo: Atlas, 2003.

MARQUEZE, E. C.; MORENO, C. R. D. C.. Satisfação no trabalho: uma breve revisão. Revista Brasileira de Saúde Ocupacional, São Paulo, v.30, n.112, p.69-79, 2005.

MASLOW, A. H.. Motivation and personality. New York: Harper, 1954.

MAXIMIANO, A. C. A.. Administração de projetos: como transformar ideias em resultados. 4 ed. São Paulo: Atlas, 2010.

MELLO, L. A. M. H. C.; NISHIMURA, A. T.; SILVA, C. M.; MADUREIRA, B. M.; CASADO, T.. Expectativas e satisfação dos alunos de graduação em administração da FEA-USP/SP em relação aos estágios. Revista de Gestão USP, São Paulo, v.14, p.61-76, 2007.

MCCLELLAND, D. C.. The achieving society. Princeton: Van Nostrand, 1961.

MCGREGOR, D.. O lado humano da empresa. 3 ed. São Paulo: Martins Fontes, 1999.

MICHEL, M.. As teorias $X$ e $Y$ e suas potencialidades de aplicação a sistemas administrativos de recursos humanos em organizações nos dias atuais. Revista Eletrônica de Administração, Porto Alegre, n.8, 2005.

MONTEIRO, G. M. S.. A influência das variáveis que compõem o clima organizacional no comprometimento das equipes de trabalho: o estudo em uma IES -RS. 2019. Monografia (MBA em Coaching e Gerenciamento de Pessoas) - Universidade Regional do Noroeste do Estado do Rio Grande do Sul, ljuí, 2019.

MOREIRA, L. K. R.; MOREIRA, L. R.; SOARES, M. G.. Educação Superior no Brasil: discussões e reflexões. Educação Por Escrito, v.9, n.1, p.134-150, 2018.

MOREIRA, S. T.; FREITAS, R. R.. Evidências de efeitos da satisfação e motivação em uma instituição pública federal de ensino superior. Brazilian Journal of Production

Engineering, v.6, n.2, 2020.

MOZZATO, A. R.; GRZYBOVSKI, D.. Análise de conteúdo como técnica de análise de dados qualitativos no campo da Administração: potencial e desafios. Revista de Administração Contemporânea, v.15, n.4, p.731-747, 2011.

OLIVEIRA, A. M. A; BRIANEZZI, A. B. L.. Estratégia de marketing interno em Instituição de Ensino Superior: óptica do docente. Revista Científica Semana Acadêmica, Fortaleza, n.000122, 2018.

OLIVEIRA, J. C. P.. Análise dos níveis de motivação de funcionários no trabalho: estudo de caso em uma empresa do ramo siderúrgico, Revista Eletrônica Gestão \& Saúde, v.6, 2015.

RIBEIRO, M. F.; PASSOS, C.; PEREIRA, P.. Motivação organizacional: fatores precursores da motivação do 
colaborador. Gestão e Desenvolvimento, n.26, p.105-131, 2018.

ROBBINS, S.. Comportamento organizacional. 9 ed. São Paulo: Pearson Prentice Hall, 2002.

ROBBINS, S. P.. Comportamento Organizacional. São Paulo: Pearson Prentice Hall, 2008.

ROBBINS, S. P.. Fundamentos do Comportamento

Organizacional. 8 ed. São Paulo: Pearson Prentice Hall, 2009.

ROBBINS, S. P.; JUDGE, T. A.. Comportamiento

organizacional. 15 ed. Guadalajara: Pearson, 2013.

RODRIGUES, M. L.; LIMENA, M. M. C.. Metodologias multidimensionais em Ciências Humanas. Brasília: Líber Livros, 2006.

SANTOS, B. S.. A motivação em diferentes cenários. Porto Alegre: EDIPUCRS, 2010.

SANTOS, G. F.; ASSUNÇÃO, J. J. O.; LIMA, A. B.; TÓFOLI, I.. Estilos de liderança: enfoque na teoria $X$ e $Y$ de Douglas McGregor. Universitári@ - Revista Científica do Unisalesiano. v.1, n.2, 2010.

SILVA, H. J. R.; SILVA, L. F.. O Endomarketing como Ferramenta Ativa na gestão de pessoas de uma Instituição de Ensino Superior de Anápolis. Revista de Magistro de Filosofia, v.11, n.23, p.93-125, 2018.

SILVA, R. O.. Teorias da Administração. São Paulo: Pioneira Thomson Learning, 2001.

SILVA, L. R. F.; MOUSQUER, L. D.; SCHADECK, M.; RODRIGUES, L. D.. A influência da motivação na produtividade do trabalho na representação comercial. Revista de Administração IMED, Passo Fundo, v.5, n.3, 2015.

SIQUEIRA, M. M. M.. Medidas do comportamento organizacional: ferramentas de diagnóstico e de gestão. Porto Alegre: Artmed, 2008.

SPECTOR, P. E.. Psicologia nas organizações. 3 ed. São Paulo: Saraiva, 2010.

VERGARA, S. C.. Gestão de Pessoas. 4 ed. São Paulo: Atlas, 2005a.

VERGARA, S. C.. Métodos de pesquisa em administração. São Paulo: Atlas, 2005b.

VERGARA, S. C.; BIANCO, A.; GOMES, A. P. C. Z.. O trabalho em equipe autogerenciadas e sua influência na motivação dos indivíduos. READ, v.12, n.1, p.18-35, 2006.

A CBPC - Companhia Brasileira de Produção Científica (CNPJ: 11.221.422/0001-03) detém os direitos materiais desta publicação. Os direitos referem-se à publicação do trabalho em qualquer parte do mundo, incluindo os direitos às renovações, expansões e disseminações da contribuição, bem como outros direitos subsidiários. Todos os trabalhos publicados eletronicamente poderão posteriormente ser publicados em coletâneas impressas sob coordenação da Sustenere Publishing, da Companhia Brasileira de Produção Científica e seus parceiros autorizados. Os (as) autores (as) preservam os direitos autorais, mas não têm permissão para a publicação da contribuição em outro meio, impresso ou digital, em português ou em tradução. 